\title{
ANALISIS HARA, TOTAL MIKROBA, SERTA PRODUKSI PADI PADA BUDIDAYA SYSTEM OF RICE INTENSIFICATION (SRI) DAN TRADITIONAL FLOODING (TF)
}

\author{
Ni Putu Giyan Adnya Antari ${ }^{1 *}$, I Nyoman Rai ${ }^{2)}$, I Wayan Budiarsa Suyasa ${ }^{3)}$ \\ ${ }^{1)}$ Program Studi Ilmu Lingkungan Universitas Udayana \\ ${ }^{2)}$ Fakultas Pertanian, Universitas Udayana \\ ${ }^{3)}$ Fakultas Matematika dan Ilmu Pengetahuan Alam, Universitas Udayana \\ ${ }^{*}$ Email: giyan.adnya.antari@gmail.com
}

\begin{abstract}
THE ANALYSIS OF SOIL NUTRIENTS, TOTAL MICROBES, AND RICE PRODUCTION ON THE SYSTEM OF RICE INTENSIFICATION (SRI) AND TRADITIONAL FLOODING (TF)
\end{abstract}

The conventional rice cultivation of Traditional Flooding (TF) seems to be wasting the water and potentially polluting the soil and water due to improper chemical fertilizers and pesticides management (Nguyen et al., 2007). System of Rice Intensification (SRI) is one of the innovative rice cultivations with the principle of single seed replantation and intermitten irrigation (IWMI, 2007). The experiment was conducted to analyze the macro nutrients, total microbes, and the rice production by combinations of nutrient and pest management in $\mathrm{TF}$ and SRI system. This study applied a nested experimental design with two factors. The first factor was the cultivation system that consisted of two levels (TF and SRI), and the second factor was nutrient and pest management consisted of three combination levels (synthetic nutrient and pest management $/ \mathrm{P}_{1}$, organic-synthetic nutrient and organic pest management $/ \mathrm{P}_{2}$, as well as organic nutrient and pest management $/ \mathrm{P}_{3}$ ). These combinations were nested to TF and SRI. Data were analyzed by ANOVA. It is found that $\mathrm{P}_{1}$ showed the highest growth and production in SRI and TF. The numbers of the height, tillers, total grains and the weight of seed per pot in SRI respectively are $87.33 \mathrm{~cm}, 22.17$ tillers, 1179.50 grains, and $32.17 \mathrm{~g}$, meanwhile in TF respectively are $78.75 \mathrm{~cm}, 17.50$ tillers, 1063.33 grains and 29.00 g. P3 shows the highest content of macro nutrients and total microbes in SRI and TF, respectively the contents of $\mathrm{C}, \mathrm{N}, \mathrm{P}$ and $\mathrm{K}$ of $\mathrm{P}_{3}$ in SRI are 6.82 \% (very high), 0.31 \% (moderate), 155.69 ppm (very high), and 1804.85 ppm (very high), meanwhile in TF respectively are $6.52 \%$ (very high), $0.25 \%$ (moderate), $52.60 \mathrm{ppm}$ (very high), and $530.79 \mathrm{ppm}$ (very high). The total microbe contents of $\mathrm{P}_{3}$ in SRI and TF respectively are $2.7 \times 10^{8} \mathrm{CFU} / \mathrm{g}$ and $3.7 \times 10^{8} \mathrm{CFU} / \mathrm{g}$. It is concluded that both in TF and SRI system (1) $\mathrm{P}_{1}$ shows the highest growth and production and (2) $\mathrm{P}_{3}$ shows the highest content of macro nutrients and total microbes. Furthermore, it is suggested that in the future the rice cultivation system should be done in a wider scale and multiple planting seasons in order to be able to precisely measure the significant difference of the rice cultivation system towards the rice growth and production.

Keywords: System of Rice Intensifications (SRI), Traditional Flooding (TF), Organic Fertilizer, Synthetic Fertilizer, Pesticide.

\section{PENDAHULUAN}

Produksi pangan di negara-negara industri telah berkembang menuju sistem produksi massal sejak tahun 1950-an. Salah satu pangan terpenting adalah beras. Menurut WWF-ICRISAT (2010), produksi pangan beras memiliki dampak lingkungan yang sangat signifikan. Praktik ini didasarkan pada penggunaan secara intensif tidak hanya tanah 
dan air, namun juga bibit, mesin, pupuk serta berbagai macam bahan kimia seperti pestisida, fungisida, herbisida, antibiotik, dan hormon (De Schutter, 2010). Praktik ini mengakibatkan buruknya kesuburan tanah, kontaminasi rantai makanan, pencemaran air oleh residu pestisida dan nitrat yang persisten, serta potensi bahaya kesehatan (Lairon, 2010). Praktik pertanian konvensional seperti sistem irigasi yang tergenang terus-menerus atau Traditional Flooding (TF) terkesan boros sumber daya air, dimana menggunakan sekitar seperempat atau sepertiga konsumsi air bersih dunia setiap tahunnya. Selain itu, praktik pertanian TF berupa pemupukan yang tidak terkendali serta penyalahgunaan pupuk anorganik dan pestisida kimia berakibat pada pencemaran air dan tanah. Budidaya TF yang menggenangi area persawahan berpotensi melepas gas metana ke udara (Nguyen et al., 2007). System of Rice Intensification (SRI) adalah salah satu inovasi sistem budidaya padi dengan konsep dasar (a) pindah tanam satu bibit per lubang dalam usia sangat muda (7-14 hari setelah semai) dengan jarak tanam longgar $(30 \mathrm{~cm}$ x $30 \mathrm{~cm}$ ) dan (b) pemberian irigasi terputus-putus tanpa penggenangan di petak sawah. Apabila konsep dasar dan sistem SRI diterapkan secara benar, maka akan diperoleh panen padi lebih besar walaupun dengan mengurangi input eksternal (air, pupuk kimia, dan sebagainya). Dengan sistem SRI air yang digunakan untuk irigasi padi dapat diefesiensi sampai 25-50\%, sehingga mampu beradaptasi terhadap perubahan iklim (IWMI, 2007). Penelitian dilakukan untuk menganalisis kandungan hara makro, total mikroba, serta pertumbuhan dan produksi padi dengan kombinasi perlakuan pemupukan dan pengendalian OPT dalam budidaya TF dan SRI.

\section{METODOLOGI}

\subsection{Rancangan Penelitian}

Penelitian ini menerapkan pola percobaan tersarang dengan dua faktor, yakni (1) budidaya SRI dan TF serta (2) pemupukan dan pengendalian OPT yang terdiri atas kombinasi pemupukan dan pengendalian OPT sintetik $\left(\mathrm{P}_{1}\right)$, pemupukan organik-sintetik dan pengendalian OPT organik $\left(\mathrm{P}_{2}\right)$, serta pemupukan dan pengendalian OPT organik $\left(\mathrm{P}_{3}\right)$. Masing-masing kombinasi perlakuan tersarang pada TF dan SRI. Data dianalis menggunakan ANOVA.

\subsection{Lokasi Penelitian}

Penelitian dilakukan di rumah plastik berukuran $3 \mathrm{~m}$ x $1.5 \mathrm{~m}$, berlokasi di Subak Antap Desa Sibanggede, Abiansemal, Badung (Gambar 1). Rumah plastik dibuat di persawahan sehingga mendapatkan sinar matahari langsung dari pagi hingga sore hari. Analisis terhadap kandungan hara dan total mikroba tanah dilaksanakan di Laboratorium Tanah Universitas Udayana Bali.

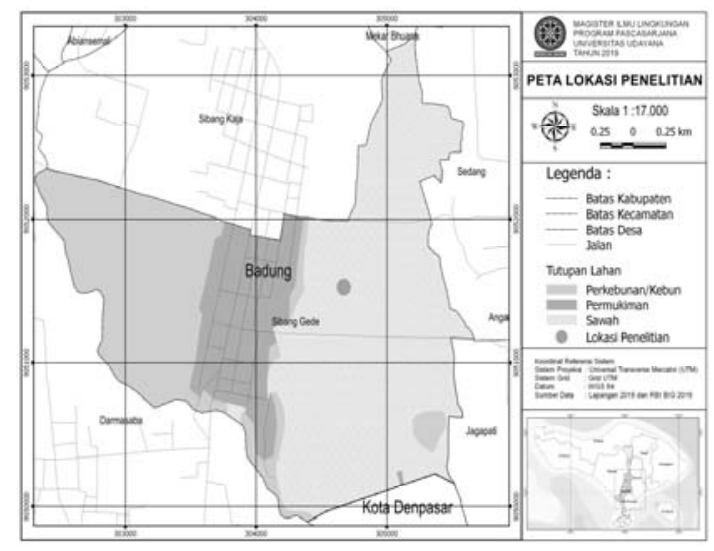

Gambar 1.

Peta Lokasi Penelitian

\subsection{Penentuan Sumber Data}

Sumber data primer dalam penelitian ini adalah data observasi pertumbuhan dan produksi padi yang mencakup tinggi tanaman dan jumlah anakan umur 14, 28, dan 56 hst, jumlah biji serta berat biji padi yang dihasilkan per pot. Selain itu data primer didapat dari hasil laboratorium uji kandungan hara C-organik, N-total, K-tersedia, P-tersedia serta total mikroba. Sumber data sekunder didapat dari hasil wawancara untuk menggali informasi terkait pola perilaku petani dalam melakukan budidaya padi secara konvensional/Traditional Flooding. Selain itu, data sekunder juga didapat melalui studi 
literatur berupa buku, jurnal nasional dan internasional.

\subsection{Variabel Penelitian}

Variabel dependen/terikat dalam penelitian ini adalah kandungan hara tanah, total mikroba, residu pestisida biji, serta pertumbuhan dan produksi padi. Variabel pertumbuhan padi yang diamati meliputi tinggi tanaman $(\mathrm{cm})$ dan jumlah anakan (batang), variabel produksi padi yang diamati meliputi total biji per pot (bulir) serta berat biji padi per pot (gr). Variabel kandungan hara makro yang diteliti meliputi kandungan C-organik (\%), N-total (\%), P-tersedia (ppm), K-tersedia (ppm), serta ditunjang oleh data $\mathrm{pH}$ dan total mikroba (CFU/gr). Variabel independen/bebas dalam penelitian ini adalah sistem budidaya padi, yakni SRI dan TF.

\subsection{Bahan Penelitian}

Bahan dan alat yang digunakan dalam penelitian ini dapat dibagi kedalam dua kelompok yakni bahan dan alat yang digunakan selama mengusahakan budidaya padi serta bahan dan alat yang digunakan dalam pengujian laboratorium. Bahan yang digunakan dalam budidaya padi meliputi: benih padi varietas MSP/Sertani-14, tanah, pupuk kandang sapi, urea, NPK, pestisida sintetik Matador, dan biopestisida (daun intaran dan tembakau). Adapun alat yang dibutuhkan, seperti: ember plastik 36 buah; timbangan digital, penyemprotan, selang air, meteran gulung, cangkul mini, nampan dan peralatan tulis.

\subsection{Instrumen Penelitian}

Adapun instrumen yang digunakan dalam penelitian ini adalah spectrophotometer untuk menganalisis kandungan P-tersedia dan Atomic Absorption Spectroscopy (AAS) untuk menganalisis kandungan K-tersedia.

\subsection{Prosedur Penelitian}

Tanah yang digunakan berasal dari tanah tegalan yang berlokasi di Green School Bali, Desa Sibangkaja, Kabupaten Badung. Tanah dihomogenasi dengan cara dikeringanginkan dalam ruang tidak tembus sinar matahari sampai tanah remah. Homogenasi tanah dilakukan selama dua minggu. Selanjutnya setiap pot percobaan diisi tanah sebanyak $10 \mathrm{~kg}$. Rumah kaca dengan ukuran 3 m x 1,5 m disiapkan. Rumah kaca dibuat dari bambu dengan atap plastik untuk menghindari pot penelitian dari guyuran hujan. Pada pemilihan varietas dan benih masing-masing sistem menggunakan varietas unggul benih MSP/Sertani-14. Benih direndam selama 1 malam agar perkecambahan benih bersamaan.

Untuk tahap persemaian, media tanah dicampur dengan bahan organik dengan perbandingan 1:1 dalam keadaan basah. Kemudian benih ditebar tidak terlalu rapat dalam nampan, lalu ditutup tipis dengan tanah. Pada sistem TF, bibit direplantasi saat berumur 20-25 hari, sedangkan pada SRI, bibit direplantasi saat berumur 7-10 hari. Untuk media tanah, baik sistem TF dan SRI menggunakan tanah yang sama yang berasal dari tanah kebun. Sebanyak 36 ember plastik berukuran tinggi $16 \mathrm{~cm}$ dan diameter $25 \mathrm{~cm}$ disiapkan sebagai pot tanam.

Dalam sistem TF, bibit ditanam sekitar 4 bibit per pot dengan kedalaman 3-4 $\mathrm{cm}$. Teknis penanaman benih dilakukan secara langsung dicabut tanpa menyertakan tanah di sekitarnya. Dalam sistem SRI, benih ditanam 2 bibit per pot serta ditanam dangkal sekitar 1-2 cm. Teknis penanaman benih dilakukan dengan menyertakan tanah di sekitar benih sekitar segenggam tangan (WWF-ICRISAT, 2010). Dalam hal penyiangan, baik sistem TF dan SRI dilakukan dengan membersihkan gulma dari tanaman induk dan dilakukan sebanyak empat kali selama musim tanam.

Mekanisme pengairan sistem TF dilakukan secara terus menerus. Pada hari ke1 hingga ke-3 setelah tanam (hst), lahan tidak diairi dan ditambah dengan pupuk urea sebanyak 0,5 g/pot, pupuk kandang sebanyak 25 g/pot, dan pupuk NPK sebanyak 0,0075 g/pot. Pada hari ke-4 hingga ke-14 hst, lahan diairi setinggi $2 \mathrm{~cm}$. Pada hari ke-15 hingga ke-20 hst, lahan diairi setinggi $2.5 \mathrm{~cm}$, kemudian lahan dikeringkan selama 6 hari 
dan diberi pupuk urea sebanyak 0,5 g/pot dan pupuk NPK sebanyak 0,0075 g/pot. Pada hari ke-30 hingga ke-50 hst, lahan kembali digenangi setinggi 2,5-5 cm. Lahan dikeringkan lagi selama 5 hari lalu diberi pupuk urea sebanyak 0,5 g/pot. Pada hari ke55 hst, lahan diairi setinggi 5-10 cm. Delapan hari sebelum panen lahan dikeringkan.

Mekanisme pengairan sistem SRI dilakukan secara intermiten. Pada hari ke-1 dan ke-3 setelah tanam (hst), lahan diairi secara macak-macak dan ditambah dengan pupuk urea sebanyak 0,5 g/pot, pupuk kandang sebanyak 25 g/pot, dan pupuk NPK sebanyak 0,0075 g/pot. Pada hari ke-4 hingga ke-10 hst, lahan diairi setinggi $1-2 \mathrm{~cm}$. Pada hari ke-11 hingga ke-14 hst, lahan dikeringkan. Pada hari ke-15 hingga ke-24 hst, lahan diairi setinggi 1-2 cm. Pada hari ke25 hingga ke-28 hst, lahan dikeringkan kembali dan diberi pupuk urea sebanyak 0,5 g/pot dan pupuk NPK sebanyak 0,0075 g/pot. Pada hari ke-29 hingga ke-38 hst, lahan diairi setinggi 1-2 cm. Pada hari ke-39 hingga ke-42 hst, lahan dikeringkan dan diberi pupuk urea sebanyak 0,5 g/pot. Pada hari ke-43 hingga ke-52 hst, lahan diairi setinggi $1-2 \mathrm{~cm}$. Pada hari ke-53 hingga ke-55 hst, lahan dikeringkan. Pada hari ke-56 hingga ke-85 hst, lahan diairi setinggi $1-2 \mathrm{~cm}$. Sepuluh hari sebelum panen lahan dikeringkan.

Kemudian perlakuan pemupukan dan pengendalian OPT dilakukan untuk menguji efektifitas dari sistem SRI ( $\left.\mathrm{B}_{1}\right)$ dan TF $\left(\mathrm{B}_{2}\right)$. Perlakuan pemupukan dan pengendalian OPT terdiri atas tiga kombinasi yakni $\mathrm{P}_{1}$ (pupuk dan pestisida sintetik), $\mathrm{P}_{2}$ (pupuk sintetik dan organik, pestisida organik), dan $\mathrm{P}_{3}$ (pupuk dan pestisida organik). Denah tata letak satuan percobaan dapat dilihat pada Gambar 2.2.

Pupuk organik berasal dari pupuk kandang sapi hasil fermentasi cap Bambu Lotus. Pupuk kandang sapi sebanyak 5 ton/ha (25 g/pot) diberikan ke dalam pot dua minggu sebelum tanam pada waktu persiapan medium tanah. Pupuk sintetik berasal dari pupuk NPK dan Urea. Pupuk NPK digunakan sebelum tanam dan umur padi 21 hst dengan dosis 150 kg/ha (0,0075 g/pot). Pupuk urea 300 kg/ha (1,5 g/pot) diberikan sebanyak tiga kali yakni 1/3 bagian waktu tanam, 1/3 bagian waktu 21 hst, dan 1/3 bagian diberikan sekitar umur 3695 hst. Pada saat pemupukan air dihentikan dan keadaan tanah macak-macak (Sampoerna, 2016).

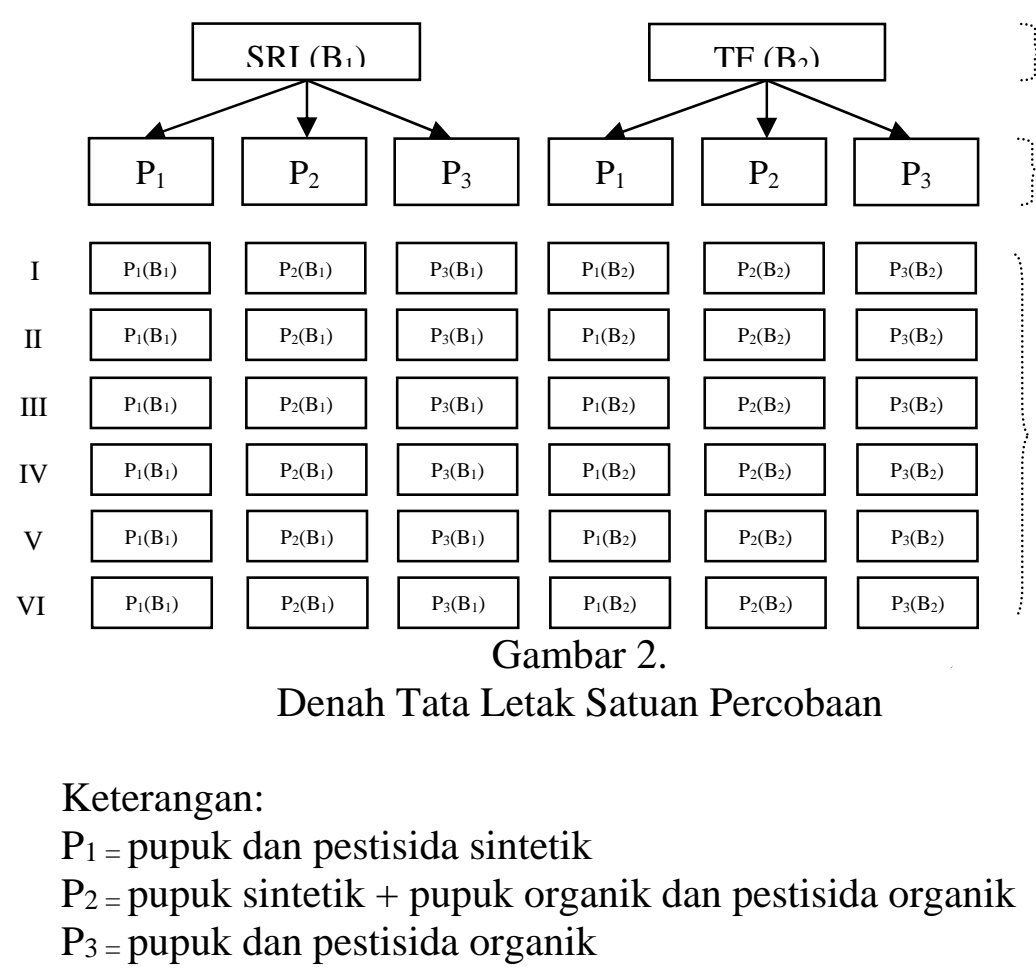

sistem

budidaya padi

perlakuan pemupukan dan pengendalian OPT

Ulangan

Jlangan 
Untuk pengendalian hama dan penyakit, pestisida sintetik yang digunakan adalah insektisida Matador (tergolong pestisida piretroid) dengan dosis $1 \mathrm{~mL} / \mathrm{L}$ air. Pestisida organik berasal dari daun intaran dan tembakau. Pestisida organik diberikan dengan mengekstrak $500 \mathrm{~g}$ daun intaran segar dalam $1 \mathrm{~L}$ air dan $100 \mathrm{~g}$ daun tembakau kering dalam $1 \mathrm{~L}$ air. Secara teori pemberian pestisida dilakukan ketika terjadi serangan hama, namun dalam penelitian ini, pemberian pestisida masing-masing sebanyak tiga kali, yakni umur 20 hari, umur 2 bulan, dan umur 2.5 bulan. Hal ini bertujuan untuk menentukan pengaruh perlakuan kombinasi pemupukan dan pemberian pestisida dalam sistem TF dan SRI terhadap kandungan hara, total mikroba, serta produksi padi.

\subsection{Analisis Data}

Data hasil pertumbuhan dan produksi tanaman dianalis menggunakan Anaylisis of Variance (ANOVA), kemudian dilanjutkan dengan uji Beda Nyata Terkecil (BNT) apabila terdapat pengaruh nyata dalam taraf perlakuan.

\section{HASIL DAN PEMBAHASAN}

Hasil analisis statistik pada perlakuan budidaya tanaman padi (B) dengan menggunakan sistem SRI ( $\left.\mathrm{B}_{1}\right)$ dan TF $\left(\mathrm{B}_{2}\right)$ menunjukkan perbedaan yang tidak nyata terhadap pertumbuhan tinggi tanaman, jumlah anakan, jumlah biji serta berat biji padi yang dihasilkan. Perlakuan pemupukan serta pengendalian OPT (P) dalam budidaya padi (B) menunjukkan perbedaan sangat nyata terhadap semua variabel yang diamati, dimana pengaruh $\mathrm{P}$ dalam $\mathrm{B}_{1}$ menunjukkan perbedaan yang sangat nyata terhadap semua variabel, sedangkan pengaruh $\mathrm{P}$ dalam $\mathrm{B}_{2}$ menunjukkan perbedaan sangat nyata terhadap variabel jumlah anakan 14, 28 dan 56 hst, jumlah biji, serta berat biji padi, berbeda nyata pada tinggi padi usia 28 dan 56, dan tidak berbeda nyata pada tinggi padi usia 14 hst (Tabel 1).

Berdasarkan hasil penelitian, pemupukan dan pengendalian OPT sintetik $\left(\mathrm{P}_{1}\right)$ memberikan pertumbuhan dan produksi padi tertinggi masing-masing pada budidaya SRI dan TF. Tinggi tanaman dan jumlah anakan pada umur 56 hst, jumlah biji, dan berat biji per pot pada sistem SRI berturutturut adalah 87,33 cm, 22,17 batang, 1.179,50 bulir, dan 32,17 g, sedangkan pada TF berturut-turut adalah 78,75 cm, 17,50 batang, turut 1.063,33 bulir dan 29,00 g (Tabel 3.2).

Tabel 1. Pengaruh Sistem Budidaya Padi dan Kombinasi Pemupukan dan Pengendalian OPT terhadap Variabel Pertumbuhan Tinggi, Jumlah Anakan, Jumlah Biji dan Berat Biji per Pot

\begin{tabular}{lcccc}
\hline \multicolumn{1}{c}{ Variabel } & \multicolumn{4}{c}{ Perlakuan } \\
& $\mathrm{B}$ & $\mathrm{P}(\mathrm{B})$ & $\mathrm{P}\left(\mathrm{B}_{1}\right)$ & $\mathrm{P}\left(\mathrm{B}_{2}\right)$ \\
\hline Tinggi Padi 14 hst (cm) & $\mathrm{NS}$ & $* *$ & $* *$ & $\mathrm{NS}$ \\
Tinggi Padi 28 hst (cm) & $\mathrm{NS}$ & $* *$ & $* *$ & $*$ \\
Tinggi Padi 56 hst (cm) & $\mathrm{NS}$ & $* *$ & $* *$ & $*$ \\
Anakan Padi 14 hst (batang) & $\mathrm{NS}$ & $* *$ & $* *$ & $* *$ \\
Anakan Padi 28 hst (batang) & $\mathrm{NS}$ & $* *$ & $* *$ & $* *$ \\
Anakan Padi 56 hst (batang) & $\mathrm{NS}$ & $* *$ & $* *$ & $* *$ \\
Jumlah Biji Padi (bulir) & $\mathrm{NS}$ & $* *$ & $* *$ & $* *$ \\
Berat Biji Padi (g) & $\mathrm{NS}$ & $* *$ & $* *$ & $* *$ \\
\hline Ku & & & $* *$
\end{tabular}

Keterangan: ns: berpengaruh tidak nyata, *: berpengaruh nyata, ${ }^{* *}$ : berpengaruh sangat nyata 
Tabel 2. Nilai Variabel Tinggi Tanaman (cm), Jumlah Anakan (batang), Jumlah Biji (bulir) serta Berat Biji Padi (g) pada Perlakuan Pemupukan dan Pengendalian OPT dalam Budidaya

\begin{tabular}{|c|c|c|c|c|c|c|c|c|}
\hline $\begin{array}{c}\text { Per- } \\
\text { lakuan }\end{array}$ & $\begin{array}{l}\text { Tinggi } \\
14 \text { hst } \\
(\mathrm{cm})\end{array}$ & $\begin{array}{l}\text { Tinggi } \\
28 \text { hst } \\
(\mathrm{cm})\end{array}$ & $\begin{array}{l}\text { Tinggi } \\
56 \text { hst } \\
(\mathrm{cm})\end{array}$ & $\begin{array}{c}\text { Jumlah } \\
\text { Anakan } \\
14 \text { hst } \\
\text { (btg) }\end{array}$ & $\begin{array}{c}\text { Jumlah } \\
\text { Anakan } \\
28 \text { hst } \\
\text { (btg) }\end{array}$ & $\begin{array}{c}\text { Jumlah } \\
\text { Anakan } \\
56 \text { hst } \\
\text { (btg) }\end{array}$ & $\begin{array}{c}\text { Jumlah } \\
\text { Biji per } \\
\text { pot } \\
\text { (bulir) }\end{array}$ & $\begin{array}{c}\text { Berat } \\
\text { Biji } \\
\text { per } \\
\text { pot (g) }\end{array}$ \\
\hline \multicolumn{9}{|c|}{ Budidaya (B) } \\
\hline$\left(B_{1}\right)$ & $35,39 a$ & $51,28 \mathrm{a}$ & $82,75 \mathrm{a}$ & $6,28 \mathrm{a}$ & $12,11 \mathrm{a}$ & $15,22 \mathrm{a}$ & $727,22 \mathrm{a}$ & $19,83 a$ \\
\hline$\left(B_{2}\right)$ & $30,25 \mathrm{a}$ & $47,67 \mathrm{a}$ & $73,19 \mathrm{a}$ & $5,89 \mathrm{a}$ & $11,33 a$ & $13,50 \mathrm{a}$ & $708,22 \mathrm{a}$ & $19,33 a$ \\
\hline BNT5\% & 6,31 & 12,85 & 23,96 & 4,05 & 8,34 & 13,78 & 1095,86 & 29,88 \\
\hline \multicolumn{9}{|c|}{ Pemupukan dan Pengendalian OPT (P) } \\
\hline$P_{1}\left(B_{1}\right)$ & $35,92 \mathrm{a}$ & $53,92 \mathrm{a}$ & $87,33 a$ & $6,83 a$ & $15,67 \mathrm{a}$ & $22,17 \mathrm{a}$ & $1179,50 \mathrm{a}$ & $32,17 \mathrm{a}$ \\
\hline $\mathrm{P}_{2}\left(\mathrm{~B}_{1}\right)$ & $38,58 \mathrm{a}$ & $56,67 \mathrm{a}$ & $93,42 \mathrm{a}$ & $7,50 \mathrm{a}$ & $13,50 \mathrm{a}$ & $16,17 \mathrm{~b}$ & $861,67 b$ & $23,50 \mathrm{~b}$ \\
\hline $\mathrm{P}_{3}\left(\mathrm{~B}_{1}\right)$ & $31,67 \mathrm{~b}$ & $43,25 b$ & $67,50 \mathrm{~b}$ & $4,50 \mathrm{~b}$ & $7,17 \mathrm{~b}$ & $7,33 \mathrm{c}$ & $140,50 \mathrm{c}$ & $3,83 c$ \\
\hline$P_{1}\left(B_{2}\right)$ & $31,83 \mathrm{a}$ & $51,33 \mathrm{a}$ & $78,75 \mathrm{a}$ & $8,17 \mathrm{a}$ & $14,17 \mathrm{a}$ & $17,50 \mathrm{a}$ & $1063,33 \mathrm{a}$ & $29,00 \mathrm{a}$ \\
\hline $\mathrm{P}_{2}\left(\mathrm{~B}_{2}\right)$ & $30,67 \mathrm{ab}$ & $47,83 \mathrm{ab}$ & $74,50 \mathrm{ab}$ & $4,83 b$ & $11,17 \mathrm{ab}$ & $14,00 \mathrm{~b}$ & $831,17 b$ & $22,67 b$ \\
\hline$P_{3}\left(B_{2}\right)$ & $28,25 b$ & $43,83 b$ & $66,33 \mathrm{~b}$ & $4,67 b$ & $8,67 \mathrm{~b}$ & $9,00 \mathrm{c}$ & $232,17 \mathrm{c}$ & $6,33 c$ \\
\hline BNT5\% & 3,24 & 5,75 & 9,30 & 1,44 & 3,06 & 3,30 & 180,82 & 4,93 \\
\hline
\end{tabular}

Keterangan: Angka yang diikuti huruf yang berbeda pada perlakuan budidaya dan kombinasi pemupukan dan pengendalian OPT terhadap variabel yang diukur menunjukkan berbeda nyata pada uji beda nyata terkecil (BNT)

Salah satu kriteria kesuburan tanah ditentukan oleh sifat kimia tanah yang dicerminkan oleh tingkat kandungan unsur hara tanah. Dari hasil penelitian ini, kandungan C-organik tanah pada sistem SRI diperoleh bahwa $\mathrm{P}_{3}$ dan $\mathrm{P}_{2}$ tergolong sangat tinggi (6,82 \% dan 5,46\%), dan $\mathrm{P}_{1}$ tergolong sedang (2,10 \%). Kandungan C-Organik tanah pada sistem $\mathrm{TF}$ menunjukkan $\mathrm{P}_{3}$ tergolong sangat tinggi (6,52 \%), $\mathrm{P}_{2}$ tergolong tinggi $(3,18 \%)$, dan $\mathrm{P}_{1}$ tergolong sedang $(2,33 \%)$ (Gambar 3).

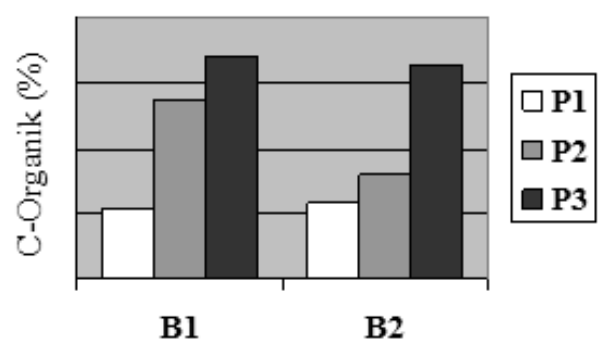

Sistem Budidaya Padi

Gambar 3.

Histogram Pengaruh Pemupukan dan Pengendalian OPT Pada Budidaya SRI dan TF terhadap Kandungan C-Organik
Kandungan N-Total tanah pada sistem SRI menunjukkan $\mathrm{P}_{3}$ tergolong sedang $(0,31 \%)$, $\mathrm{P}_{2}$ tergolong rendah $(0,13 \%)$, dan $\mathrm{P}_{1}$ tergolong sangat rendah $(0,08 \%)$. Kandungan N-Total tanah pada sistem TF menunjukkan $\mathrm{P}_{3}$ dan $\mathrm{P}_{2}$ tergolong sedang $(0,25 \%$ dan 0,23 $\%)$, dan $\mathrm{P}_{1}$ tergolong sangat rendah (0,08 \%) (Gambar 4.)

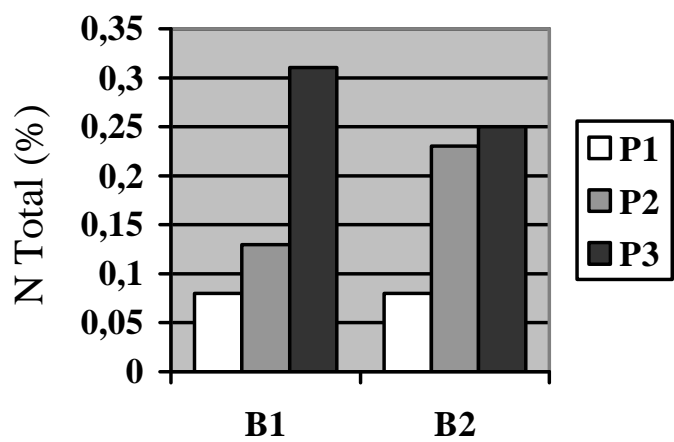

Sistem Budidaya Padi

Gambar 4.

Histogram Pengaruh Pemupukan dan

Pengendalian OPT Pada Budidaya SRI dan TF terhadap Kandungan N-total 102 
Kandungan P Tersedia pada sistem SRI menunjukkan $\mathrm{P}_{3}$ dan $\mathrm{P}_{2}$ tergolong sangat tinggi (155,69 ppm dan 119,42 ppm) dan $\mathrm{P}_{1}$ tergolong sedang (24,71 ppm). Kandungan $\mathrm{P}$ Tersedia pada sistem TF menunjukkan $\mathrm{P}_{3}$ tergolong sangat tinggi (52,60 ppm), serta $\mathrm{P}_{2}$ dan $\mathrm{P}_{1}$ tergolong sedang (20,99 $\mathrm{ppm}$ dan 17,44 ppm) (Gambar 5).

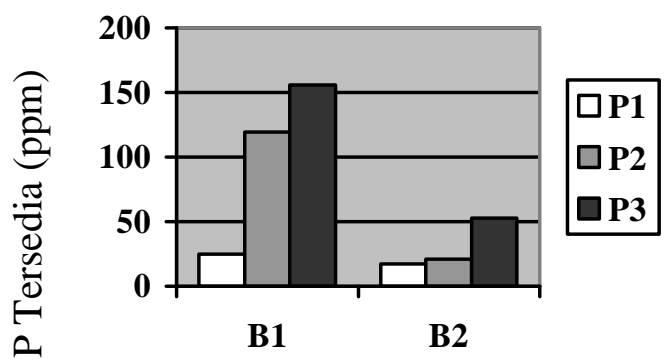

Sistem Budidaya Padi

Gambar 5

Histogram Pengaruh Pemupukan dan Pengendalian OPT Pada Budidaya SRI dan TF terhadap Kandungan P-tersedia

Kandungan $\mathrm{K}$ Tersedia pada pada sistem SRI menunjukkan $\mathrm{P}_{3}$ dan $\mathrm{P}_{2}$ tergolong sangat tinggi (1804,85 ppm dan 1226,73 $\mathrm{ppm})$, dan $\mathrm{P}_{1}$ tergolong tinggi (314,71 ppm). Kandungan $\mathrm{K}$ Tersedia pada sistem TF menunjukkan $\mathrm{P}_{3}$ tergolong sangat tinggi (530,79 ppm), serta $\mathrm{P}_{2}$ dan $\mathrm{P}_{3}$ tergolong sedang (209,78\% dan 179,18\%) (Gambar 6).

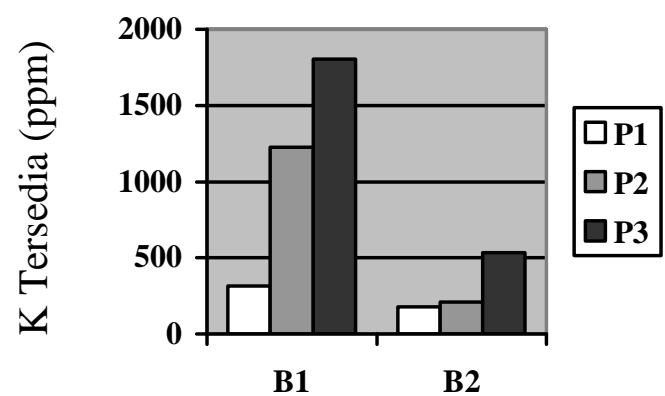

Sistem Budidaya Padi

Gambar 6.

Histogram Pengaruh Pemupukan dan Pengendalian OPT Pada Budidaya SRI dan TF terhadap Kandungan K-tersedia

Berdasarkan hasil yang telah diuraikan di atas, maka secara umum dapat dinyatakan bahwa masing-masing sistem SRI dan TF menunjukkan bahwa $\mathrm{P}_{3}$ memiliki kecenderungan kandungan hara tertinggi (COrganik, N-Total, P Tersedia dan K Tersedia). Tinggi rendahnya kandungan hara diduga disebabkan oleh kemampuan jenis pupuk melepas unsur hara dalam tanah. Hal tersebut didukung oleh pendapat Prastya (2016) yang menyatakan bahwa unsur-unsur hara di dalam bahan organik dilepaskan secara perlahan-lahan melalui proses mineralisasi sehingga akan sangat membantu kesuburan tanah.

Perlakuan pemupukan organik $\left(\mathrm{P}_{3}\right)$ pada masing-masing sistem SRI maupun TF memberikan total mikroba tertinggi dibandingkan dengan pemupukan campuran organik-sintetik, dan pemupukan sintetik memberikan total mikroba terendah. Nilai total mikroba $\mathrm{P}_{3}$ pada SRI dan TF berturutturut adalah 2,7 x $10^{8} \mathrm{CFU} / \mathrm{g}$ dan 3,7 $\times 10^{8}$ CFU/g (Gambar 7). Tingginya total mikroba pada $\mathrm{P}_{3}$ disebabkan oleh pemberian pupuk organik yang merupakan bahan makanan dari mikroba itu sendiri, yang selanjutnya dirombak menjadi unsur hara tersedia dalam tanah. Hal tersebut ditunjang oleh pendapat Irfan (2014) yang menyatakan bahwa indikator jumlah dan jenis mikroba dalam tanah dipengaruhi tingkat ketersediaan bahan organik dalam tanah yang cukup, suhu yang sesuai, ketersedian air yang cukup dan kondisi ekologi tanah yang mendukung.

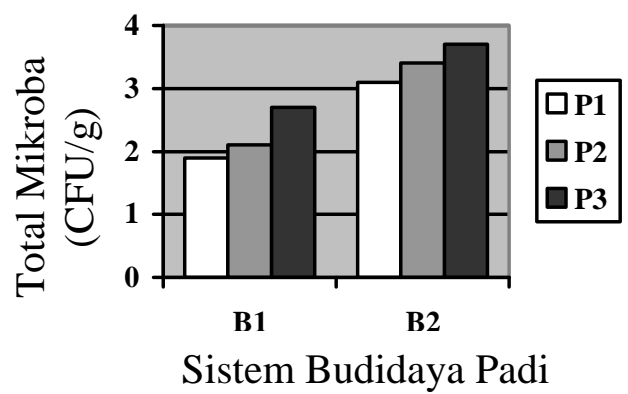

Gambar 7.

Histogram Pengaruh Pemupukan dan Pengendalian OPT Pada Budidaya SRI dan TF terhadap Total Mikroba Tanah 


\section{SIMPULAN DAN SARAN}

\subsection{Simpulan} lain:

Simpulan dari hasil penelitian ini antara

1. Pemupukan dan pengendalian OPT sintetik $\left(\mathrm{P}_{1}\right)$ memberikan pertumbuhan dan produksi padi tertinggi masingmasing pada budidaya SRI dan TF. Tinggi tanaman dan jumlah anakan pada umur 56 hst, jumlah biji, dan berat biji per pot pada sistem SRI adalah 87,33 cm, 22,17 batang, 1.179,50 bulir, dan 32,17 g, sedangkan pada TF berturut-turut adalah 78,75 cm, 17,50 batang, turut 1.063,33 bulir dan 29,00 g.

2. Pemupukan dan pengendalian OPT organik $\left(\mathrm{P}_{3}\right)$ memberikan kandungan hara makro (C-organik, N-total, Ptersedia, K-tersedia) dan total mikroba tertinggi masing-masing pada budidaya SRI dan TF. Nilai C, N, P dan $\mathrm{K}$ berturut-turut dalam SRI sebesar 6,82 \% (sangat tinggi), 0,31\% (sedang), 155,69 ppm (sangat tinggi), dan 1.804,85 ppm (sangat tinggi). Nilai C, N, P dan K berturut-turut dalam TF sebesar 6,52 \% (sangat tinggi), 0,25 \% (sedang), 52,60 ppm (sangat tinggi), dan 530,79 ppm (sangat tinggi).

3. Pemupukan dan pengendalian OPT sintetik $\left(\mathrm{P}_{1}\right)$ tidak meninggalkan residu pestisida masing-masing pada budidaya SRI dan TF.

\subsection{Saran}

Saran-saran yang bisa diajukan dari penelitian ini antara lain:

1. Diperlukan adanya penelitian lanjutan di lapangan dalam skala luas dan musim tanam yang berkesinambungan untuk menguji signifikansi pertumbuhan dan produksi padi serta kesuburan tanah pada sistem budidaya SRI dan TF.

2. Untuk optimalisasi produksi padi dan meningkatkan kandungan hara tanah untuk mendukung pertanian berkelanjutan, sebaiknya dilakukan dengan kombinasi perlakuan pemupukan organik dan sintetik dengan perbandingan pupuk organik 5 ton/ha, pupuk NPK $150 \mathrm{~kg} / \mathrm{ha}$, dan pupuk urea $300 \mathrm{~kg} / \mathrm{ha}$.

3. Diperlukan adanya penelitian dan identifikasi lebih lanjut tentang besaran gas metana yang dihasilkan oleh aktivitas mikroba dari budidaya padi sistem TF dan SRI.

\section{DAFTAR PUSTAKA}

De Schutter, O. 2010. The Shift to Low Carbon Agriculture is Becoming a Matter of Urgency. Statement by the UN Special Rapporteur on the Right to Food. World Food Day - 16 October 2010.

Irfan, M. 2014. Isolasi dan Enumerasi Bakteri Tanah Gambut Di Perkebunan Kelapa Sawit PT. Tambang Hijau Kecamatan Tambang Kabupaten Kampar. Kepala Lab. Patologi, Entomologi dan Mikrobiologi Fak.Pertanian dan Peternakan UIN Riau. Agroteknologi, 5 (1): 1-8.

IWMI. 2007. Rice: Feeding the Billions, Chapter 14, in Water for Food, Water for Life: A Comprehensive Assessment of Water Management in Agriculture. Earthscan, London, and International Water Management Institute, Colombo.

Lairon, D. 2010. Nutritional Quality and Safety of Organic Food. A review. Agron. Sustain. Dev. 30 (1), 33-41. 
Nguyen, V.T., Q.T. Nguyen and V.A. Nguyen. 2007. Influence of onfarm water management to the methane emissions in the Red River Delta Area- Vietnam. Vietnam National Commission on Large Dams [www.vncold.vn]

Prastya. 2016. Pengaruh Jenis dan Komposisi Pupuk Kandang Ayam dan Pupuk NPK Terhadap Serapan Nitrogen dan Hasil Bawang
Merah (Allium Ascalonicum L.) Varietas Lembah Palu Di Entisol Sidera.

WWF-ICRISAT. 2010. More Rice With Less Water - System of Rice Intensification, Second Edition in Draft. Joint Dialogue Project of Worldwide Fund for Nature and International Crop Research Institute for the Semi-Arid Tropics on 'Food, Water and Environment, Hyderabad. 